\title{
Quantitative Changes in Hydrocarbons over Time in Fecal Pellets of Incisitermes minor May Predict Whether Colonies Are Alive or Dead
}

\author{
Vernard R. Lewis • Lori J. Nelson • Michael I. Haverty • \\ James A. Baldwin
}

Received: 30 April 2010 /Revised: 1 September 2010 /Accepted: 16 September 2010 /Published online: 30 September 2010

(C) The Author(s) 2010. This article is published with open access at Springerlink.com

\begin{abstract}
Hydrocarbon mixtures extracted from fecal pellets of drywood termites are species-specific and can be characterized to identify the termites responsible for damage, even when termites are no longer present or are unable to be recovered easily. In structures infested by drywood termites, it is common to find fecal pellets, but difficult to sample termites from the wood. When fecal pellets appear after remedial treatment of a structure, it is difficult to determine whether this indicates that termites in the structure are still alive and active or not. We examined the hydrocarbon composition of workers, alates, and soldiers of Incisitermes minor (Hagen) (family Kalotermitidae) and of fecal pellets of workers. Hydrocarbons were qualitatively similar among castes and pellets. Fecal pellets that were aged for periods of $0,30,90$, and 365 days after collection were qualitatively similar across all time periods, however, the relative quantities of certain individual hydrocarbons changed over time, with 19 of the 73 hydrocarbon peaks relatively increasing or decreasing. When the sums of the positive and negative slopes of these 19 hydrocarbons were indexed, they produced a highly significant linear correlation $\left(R^{2}=0.89\right)$. Consequently, the quantitative differences of these hydrocarbons peaks can be used to determine the age of worker fecal pellets, and thus help determine whether the colony that produced them is alive or dead.
\end{abstract}

\footnotetext{
V. R. Lewis $\cdot$ M. I. Haverty $(\bowtie)$

Environmental Science, Policy, and Management, College of Natural Resources, University of California, Berkeley, CA 94720, USA

e-mail: mhaverty@berkeley.edu
}

L. J. Nelson · M. I. Haverty · J. A. Baldwin Pacific Southwest Research Station, USDA Forest Service, P.O. Box 245, Berkeley, CA 94701, USA
Key Words Colony survival · Cuticular hydrocarbons . Drywood termites $\cdot$ Fecal pellets $\cdot$ Frass $\cdot$ Kalotermitidae . Isoptera

\section{Introduction}

Drywood termites cause significant damage to wood in structures in the United States, with two species, Incisitermes minor (Hagen) and Cryptotermes brevis (Walker), being responsible for the majority of damage (Su and Scheffrahn, 1990; Grace, 2009). The economic cost of control and repair of damage is second only to that for subterranean termites (Su and Scheffrahn, 1990). Remedial control of drywood termites in the United States relies primarily on either (1) fumigation of the entire structure with a toxic gas or heated air, or (2) localized chemical or physical treatments designed to eradicate small, localized colonies (Lewis and Haverty, 1996; Lewis, 2008; Lewis and Rust, 2009). Fumigation treatments are likely to kill all of the termites in a structure, while localized treatments can destroy all termites in a colony, provided the treatment is delivered to the entire gallery system.

The size, number, and dispersion of drywood termite colonies in a structure can vary greatly, depending on the age of the infestation and the success of preventative or remedial treatments. Drywood termite colonies also are considered single piece nesters, i.e., they nest within their food source and do not forage from the nesting site to a food source (Abe, 1987). In fact, large, dispersed colonies (or even small colonies) can live in a single piece of wood or in multiple pieces of wood that are joined together (Grace et al., 2009). Further complicating control of drywood termites by localized treatments is the possibility of numerous small, undetected colonies residing in a structure. 
Drywood termites are cryptic, seldom leaving obvious or visible external signs of their presence in wood. A commonly used sign for determining the presence of drywood termites is the occurrence of fecal pellets, ejected through a "kick-out hole" in the external surface of wood from the internal galleries (Ebeling, 1975). These pellets often are found as conical piles or are scattered on horizontal surfaces below infested wood. These hexagonally sided pellets are diagnostic for drywood termites, and can be used to distinguish damage from that by other wood-destroying insects (Ebeling, 1975; Moore, 1992).

Grace and Yamamoto (2009) demonstrated the relationship between the cellulose and lignin content of the food utilized by small groups of $C$. brevis and Incisitermes immigrans (Light), and the quantity of fecal pellets produced over time. They also discussed the use of the size and number of fecal pellets for estimating both size and age of drywood termite colonies.

Drywood termites excrete feces in the form of hard, even-shaped fecal pellets. These fecal pellets contain the same mixture of hydrocarbons as the insects that produced them, albeit in slightly different proportions (Haverty et al., 2005). Because cuticular hydrocarbons are species specific in termites (Page et al., 2002), pellets can be used to identify the termite species that produced them. Rather than simply signaling the general presence of termites or providing a diagnosis of the species of termite inhabiting the wood, we postulated that these pellets could be chemically characterized so as to determine the status of a colony as active (alive) or inactive (dead).

Here, we report quantification of the hydrocarbons in pellets of I. minor aged for up to 1 year after they were produced. We document the changes in proportions of selected hydrocarbons as an indication of the length of time since the pellets were excreted.

\section{Methods and Materials}

Collection of Termites and Preparation of Termite Containment Unit Termites, I. minor, were removed from one naturally infested board $(98.9 \times 13.3 \times 271.8 \mathrm{~cm})$ collected on 19 July 2006 from Lakeview, California, and stored at the University of California Richmond Field Station. The board was cut across the grain into pieces, $5-8 \mathrm{~cm}$ thick, and stored at room temperature. A wood chisel was used to separate pieces of wood into smaller pieces, $0.5-1.0 \mathrm{~cm}$ thick. Termites were removed from all visible galleries with forceps. All remaining live termites, including soldiers and primary reproductives (alates), were placed in a termite containment unit (TCU). Termites thus collected were likely from a large mixed colony (Booth et al., 2010) or from multiple colonies. We were not able to assign the various galleries in the wood to any particular colony.
Fifteen birch tongue depressors were bundled together, and three equally spaced holes drilled across the length of the bundle using a $2.8-\mathrm{mm}$ bit. Bamboo skewers, $10-13 \mathrm{~cm}$ in length, were inserted into each of the three holes in the bundle of tongue depressors. Spaces, 3-6 mm, were left between each tongue depressor allowing termites access to all tongue depressors. Two sets of skewered tongue depressors were placed into a clean plastic container $(17.5 \times 12.5 \times 6 \mathrm{~cm})$, one on top of the other, such that the tongue depressors on the top layer fit into the gaps created by the tongue depressors on the bottom layer. Tongue depressors were lightly misted with water, and then 6,662 drywood termites (a mixture of pseudergates or workers, alates, and soldiers) were placed in the TCU. TCUs, with termites, were maintained in a dark cabinet in the laboratory under ambient conditions prior to collection of fecal pellets. A single colony or a mixture of two or more colonies, representing a single location within California, was prepared in this manner.

Pellet Collection and Aging Process After all the TCUs had acclimated to laboratory conditions over several weeks, new holding chambers were prepared. A total of 3,402 live workers were transferred to a new TCU. All wood debris, pellets, dead termites, and damaged tongue depressors were discarded. The termites in the new holding chambers were maintained in the laboratory under ambient conditions for 2 weeks. At the end of this period, all pellets were removed, and sub-samples collected and readied for the aging study. Concurrently, three samples of 20 workers, three samples of 20 alates, and one sample of 20 soldiers were also collected for hydrocarbon analysis. Live termites were placed in a 20-ml scintillation vial and frozen until extraction.

Fecal pellets were separated from debris by sequentially sifting them through successively smaller sieves (Haverty et al., 2005). It was important to avoid contamination of samples with any extrinsic hydrocarbons. Thus, all substances such as hand lotion, lip balm, Parafilm, and waxed paper were kept away from the work area. Gloves were worn when handling pellets, and implements that came in contact with pellets were wiped with a paper towel dampened with absolute ethanol to remove any oils or waxes. Pellets were separated from fine debris by removing individual pellets with forceps or with an aspirator, until a sample weighing approximately $200 \mathrm{mg}$ was obtained.

In developing this protocol we made one estimate and one critical assumption. The estimate was that at least 1,000 pellets were needed for each hydrocarbon analysis (based on preliminary analyses of pellets collected from drywood termites maintained in our laboratory). The critical assumption was based on work conducted by Scheffrahn et al. (1997) using C. brevis and I. snyderi (Light) from southern Florida. In that study, 40 I. snyderi 
Fig. 1 Total ion chromatogram of cuticular hydrocarbons from a workers of Incisitermes minor (Hagen) and b from fecal pellets from the same collection. Acronyms for hydrocarbons are derived as follows: $X$-me location of methyl groups, the total number of carbons $C X X$ in the hydrocarbon component excluding the methyl branch(es), and $C X X: Y$ the number of double bonds following a colon

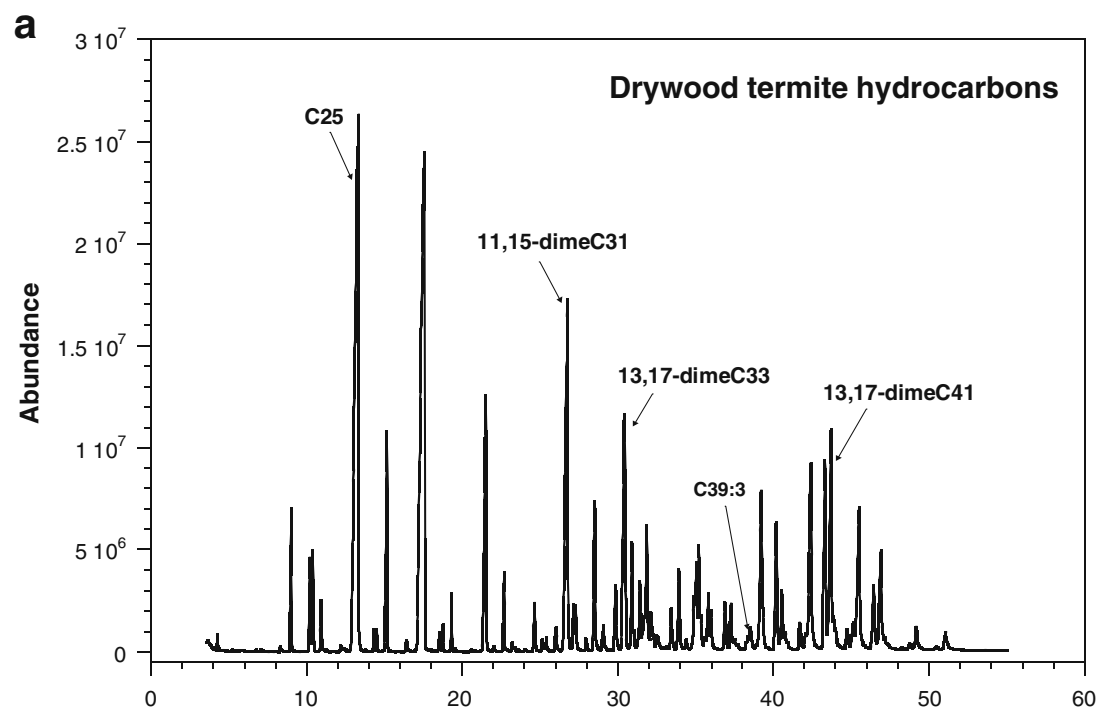

b

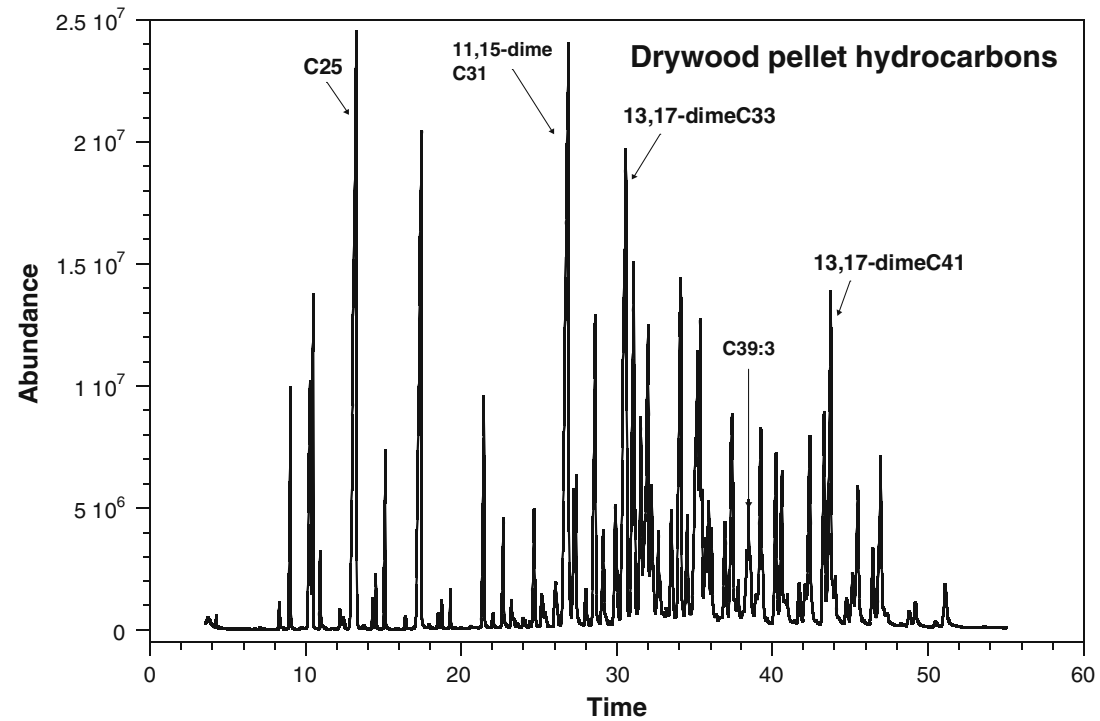

(pseudergates or workers) produced 573 pellets over 4 weeks, slightly less than 150 pellets/wk or about 3.5 pellets/individual/wk. In a study with small groups of C. brevis and I. immigrans, Grace and Yamamoto (2009) found that these species produced 4.9 to 7.0 pellets/ individual/wk. For our study, we assumed that $I$. minor would produce pellets at roughly the same rate and, therefore, we needed about 3,000 to 5,000 individuals in a TCU for this study. We prepared one TCU to collect the requisite quantity of fecal pellets.

Four sub-sampling intervals, each replicated three times, were used: $0,30,90$, and 365 days from the initial collection date. Sub-samples were stored in clean, 20-ml scintillation vials, sealed with $1.5 \times 1.5 \mathrm{~mm}$ mesh screen. Vials were stored in a dark cabinet at the University of California Richmond Field Station at ambient temperature.
Voucher samples of I. minor pseudergates or workers and soldiers from this study (fresh, not dried) were preserved in $85 \%$ ethanol and deposited in the Essig Museum, University of California at Berkeley (Haverty et al., 2005).

Extraction Procedure and Characterization of Hydrocarbons Hydrocarbons from workers, alates, soldiers, and fecal pellets of I. minor were extracted, characterized, and quantified as previously reported (Haverty et al., 2005). Frozen termite samples were thawed and dried at $70^{\circ} \mathrm{C}$ for approximately $1 \mathrm{~h}$ before extraction. Each sub-sample of fecal pellets or termites was placed in a $20-\mathrm{ml}$ scintillation vial, and immersed in $10 \mathrm{ml}$ of $n$-hexane for $10 \mathrm{~min}$. After extraction, hydrocarbons were separated from other compounds through $4 \mathrm{~cm}$ of activated Sigma silica gel (70-230 mesh) in 
Table 1 Relative abundance ${ }^{\mathrm{a}}$ of hydrocarbons from pseudergates, alates, soldiers, and fecal pellets of Incisitermes minor (Hagen)

\begin{tabular}{|c|c|c|c|c|}
\hline Hydrocarbons ${ }^{\mathrm{b}}$ & Pseudergates $N=3$ & Alates $N=3$ & Soldiers $N=1$ & Fecal pellets $N=12$ \\
\hline $2-\mathrm{meC} 22^{\mathrm{c}}$ & $0.06(0.02)$ & $0.08(0.02)$ & 0.09 & $0.11(0.02)$ \\
\hline$n-\mathrm{C} 23$ & $1.30(0.06)$ & $1.34(0.05)$ & 1.48 & $1.35(0.18)$ \\
\hline 2-meC23 & $1.45(0.40)$ & $1.72(0.35)$ & 2.11 & $2.13(0.28)$ \\
\hline $3-\mathrm{meC} 23$ & $1.31(0.38)$ & $1.38(0.30)$ & 1.71 & $2.06(0.29)$ \\
\hline$n-\mathrm{C} 24$ & $0.46(0.01)$ & $0.43(0.02)$ & 0.48 & $0.32(0.05)$ \\
\hline $2-\mathrm{meC} 24^{\mathrm{c}}$ & $0.13(0.03)$ & $0.19(0.03)$ & 0.19 & $0.15(0.02)$ \\
\hline $3-\mathrm{meC} 24^{\mathrm{c}}$ & $0.08(0.02)$ & $0.10(0.02)$ & 0.12 & $0.11(0.02)$ \\
\hline$n-\mathrm{C} 25$ & $16.35(0.16)$ & $11.75(0.40)$ & 12.64 & $8.65(1.05)$ \\
\hline $2-\mathrm{meC} 25$ & $0.18(0.01)$ & $0.27(0.01)$ & 0.24 & $0.14(0.02)$ \\
\hline 3-meC25 & $0.23(0.04)$ & $0.36(0.04)$ & 0.34 & $0.26(0.03)$ \\
\hline$n-\mathrm{C} 26$ & $2.25(0.15)$ & $1.17(0.07)$ & 1.51 & $0.87(0.12)$ \\
\hline $2-\mathrm{meC} 26^{\mathrm{c}}$ & $0.14(0.01)$ & $0.13(0.01)$ & 0.14 & $0.07(0.01)$ \\
\hline$n-\mathrm{C} 27$ & $14.04(0.55)$ & $6.81(0.31)$ & 10.05 & $5.91(0.65)$ \\
\hline $2-\mathrm{meC} 27^{\mathrm{c}}$ & $0.13(0.01)$ & $0.09(0.01)$ & 0.13 & $0.06(0.01)$ \\
\hline 3-meC27 & $0.20(0.01)$ & $0.19(0.01)$ & 0.25 & $0.12(0.01)$ \\
\hline$n-\mathrm{C} 28^{\mathrm{c}}$ & $0.43(0.05)$ & $0.17(0.01)$ & 0.35 & $0.15(0.03)$ \\
\hline$n-\mathrm{C} 29$ & $3.38(0.33)$ & $1.27(0.07)$ & 2.97 & $1.38(0.18)$ \\
\hline $11-\mathrm{meC} 29^{\mathrm{c}}$ & $0.06(0.01)$ & $0.15(0.01)$ & 0.10 & $0.09(0.01)$ \\
\hline 9,13-dimeC29 & $0.70(0.02)$ & $0.82(0.01)$ & 0.91 & $0.63(0.06)$ \\
\hline 9,13,17-trimeC29 & $0.11(0.02)$ & $0.27(0.00)$ & 0.16 & $0.22(0.03)$ \\
\hline$n-\mathrm{C} 30^{\mathrm{c}}$ & $0.04(0.00)$ & $0.07(0.00)$ & 0.10 & 0.00 \\
\hline $13-\mathrm{meC} 30^{\mathrm{c}}$ & $0.01(0.02)$ & $0.08(0.00)$ & 0.04 & 0.00 \\
\hline 10,14-dimeC30 & $0.64(0.06)$ & $1.45(0.02)$ & 0.88 & $0.90(0.03)$ \\
\hline 10,14,18-trimeC 30 & $0.18(0.02)$ & $0.43(0.01)$ & 0.24 & $0.28(0.02)$ \\
\hline$n-\mathrm{C} 31^{\mathrm{c}}$ & $0.14(0.01)$ & $0.10(0.01)$ & 0.20 & $0.09(0.01)$ \\
\hline $15-; 13-; 11-; 9-\mathrm{meC} 31^{\mathrm{d}}$ & $0.36(0.03)$ & $0.82(0.01)$ & 0.42 & $0.49(0.02)$ \\
\hline $13,17-; 11,15-\operatorname{dimeC} 31^{\mathrm{d}}$ & $7.45(0.68)$ & $13.74(0.52)$ & 8.55 & $10.67(1.80)$ \\
\hline 9,13,17-trimeC31 & $0.57(0.05)$ & $1.19(0.02)$ & 0.72 & $0.89(0.06)$ \\
\hline 7,11,15-trimeC31 & $0.54(0.04)$ & $0.99(0.01)$ & 0.72 & $0.81(0.09)$ \\
\hline $14-; 12-\mathrm{meC} 32^{\mathrm{d}}$ & $0.17(0.01)$ & $0.33(0.02)$ & 0.19 & $0.27(0.03)$ \\
\hline 12,16-dimeC32 & $2.01(0.14)$ & $3.57(0.05)$ & 2.22 & $2.97(0.28)$ \\
\hline $10,14,18-; 8,12,16$-trimeC $32^{\mathrm{d}}$ & $0.46(0.03)$ & $0.80(0.02)$ & 0.61 & $0.82(0.06)$ \\
\hline $15-; 13-\mathrm{meC} 33^{\mathrm{d}}$ & $0.93(0.05)$ & $1.57(0.03)$ & 0.92 & $1.30(0.08)$ \\
\hline $13,17-; 11,15-; 9,13-\operatorname{dimeC} 33^{\mathrm{d}}$ & $4.63(0.31)$ & $6.87(0.11)$ & 5.11 & $7.41(1.03)$ \\
\hline 9,13,17-trimeC33 & $1.30(0.08)$ & $2.02(0.02)$ & 1.86 & $3.47(0.33)$ \\
\hline 7,13,17-trimeC 33 & $0.21(0.02)$ & $0.32(0.01)$ & 0.32 & $0.47(0.07)$ \\
\hline $\mathrm{C} 35: 3$ & $1.01(0.03)$ & $2.93(0.17)$ & 1.64 & $1.76(0.17)$ \\
\hline $\mathrm{C} 35: 2^{\mathrm{d}}$ & $2.31(0.06)$ & $4.46(0.14)$ & 2.71 & $3.55(0.15)$ \\
\hline 12,16-dimeC34; C35: $1^{\mathrm{c}, \mathrm{d}}$ & $0.68(0.02)$ & $1.16(0.03)$ & 0.85 & $1.40(0.10)$ \\
\hline $10,14,18-; 8,12,16$-trimeC34 $34^{\mathrm{c}, \mathrm{d}}$ & $0.28(0.00)$ & $0.50(0.04)$ & 0.45 & $0.89(0.14)$ \\
\hline $15-; 13-; 11-\mathrm{meC} 35^{\mathrm{d}}$ & $0.56(0.02)$ & $0.85(0.05)$ & 0.67 & $1.11(0.09)$ \\
\hline 13,17-dimeC35 & $1.27(0.09)$ & $1.96(0.02)$ & 1.83 & $3.95(0.46)$ \\
\hline 9,13,17-trimeC35 & $0.14(0.01)$ & $0.28(0.03)$ & 0.27 & $0.93(0.14)$ \\
\hline $\mathrm{C} 37: 3^{\mathrm{d}}$ & $1.74(0.06)$ & $3.33(0.16)$ & 2.72 & $3.28(0.34)$ \\
\hline $\mathrm{C} 37: 2^{\mathrm{d}}$ & $1.67(0.06)$ & $2.55(0.08)$ & 2.18 & $2.90(0.10)$ \\
\hline 12,16-dimeC36 & $0.17(0.01)$ & $0.34(0.02)$ & 0.28 & $0.71(0.08)$ \\
\hline $\mathrm{C} 37: 1$ & $0.78(0.02)$ & $0.76(0.03)$ & 0.81 & $0.83(0.06)$ \\
\hline $10,14,18$-trimeC $36 ; \mathrm{C} 37: 1^{\mathrm{c}, \mathrm{d}}$ & $0.44(0.03)$ & $0.35(0.05)$ & 0.43 & $0.58(0.10)$ \\
\hline $13 ; 11-\mathrm{meC} 37^{\mathrm{d}}$ & $0.71(0.01)$ & $0.60(0.04)$ & 0.77 & $0.89(0.14)$ \\
\hline
\end{tabular}


Table 1 (continued)

\begin{tabular}{|c|c|c|c|c|}
\hline Hydrocarbons ${ }^{\mathrm{b}}$ & Pseudergates $N=3$ & Alates $N=3$ & Soldiers $N=1$ & Fecal pellets $N=12$ \\
\hline $13,17-; 11,15-\operatorname{dimeC} 37^{\mathrm{d}}$ & $0.87(0.05)$ & $1.27(0.01)$ & 1.25 & $2.13(0.22)$ \\
\hline 9,13,17-trimeC 37 & $0.09(0.01)$ & $0.13(0.01)$ & 0.13 & $0.30(0.06)$ \\
\hline $\mathrm{C} 39: 3^{\mathrm{d}}$ & $0.09(0.02)$ & $0.18(0.02)$ & 0.29 & $0.49(0.16)$ \\
\hline $\mathrm{C} 39: 3 ; 12-\mathrm{meC} 38^{\mathrm{d}}$ & $0.49(0.04)$ & $0.56(0.03)$ & 0.76 & $1.03(0.18)$ \\
\hline 14,$18 ; 12,16-\operatorname{dimeC} 38^{\mathrm{d}}$ & $0.02(0.03)$ & $0.14(0.01)$ & 0.14 & $0.24(0.04)$ \\
\hline C39:1; 10,14,18-trimeC38 & $2.73(0.19)$ & $1.73(0.04)$ & 2.53 & $1.74(0.23)$ \\
\hline $13-; 11-\mathrm{meC} 39^{\mathrm{d}}$ & $1.75(0.09)$ & $1.03(0.03)$ & 1.70 & $1.26(0.20)$ \\
\hline $13,17-; 11,15-\operatorname{dimeC} 39^{\mathrm{d}}$ & $0.90(0.01)$ & $1.04(0.14)$ & 1.36 & $1.44(0.08)$ \\
\hline $9,13,17$-trimeC $39^{c}$ & $0.41(0.03)$ & $0.17(0.09)$ & 0.11 & $0.20(0.03)$ \\
\hline $12-; 10-\mathrm{meC} 40^{\mathrm{d}}$ & $0.38(0.05)$ & $0.20(0.01)$ & 0.35 & $0.26(0.07)$ \\
\hline 12,16-dimeC40 & $0.27(0.00)$ & $0.27(0.02)$ & 0.34 & $0.32(0.05)$ \\
\hline $\mathrm{C} 41: 1$ & $3.31(0.27)$ & $1.70(0.04)$ & 2.79 & $1.58(0.25)$ \\
\hline $13-; 11-\mathrm{meC} 41^{\mathrm{d}}$ & $2.78(0.20)$ & $1.45(0.06)$ & 2.59 & $1.74(0.31)$ \\
\hline $13,17-; 11,15$-dimeC $41^{\mathrm{d}}$ & $3.34(0.13)$ & $2.90(0.15)$ & 4.00 & $3.33(0.19)$ \\
\hline 9,13,17-trimeC41 & $0.79(0.02)$ & $0.30(0.02)$ & 0.33 & $0.42(0.19)$ \\
\hline $12-; 10-\mathrm{meC} 42^{\mathrm{d}}$ & $0.30(0.03)$ & $0.15(0.01)$ & 0.25 & $0.26(0.27)$ \\
\hline 12,16-dimeC42 & $0.48(0.04)$ & $0.37(0.02)$ & 0.52 & $0.47(0.12)$ \\
\hline $\mathrm{C} 43: 1$ & $2.72(0.28)$ & $1.25(0.06)$ & 2.27 & $1.31(0.26)$ \\
\hline $15-; 13-\mathrm{meC} 43^{\mathrm{d}}$ & $1.00(0.14)$ & $0.46(0.05)$ & 0.87 & $0.61(0.16)$ \\
\hline 13,17-dimeC43 & $1.99(0.16)$ & $1.18(0.16)$ & 1.93 & $1.68(0.28)$ \\
\hline 14,18 -dimeC $44^{\mathrm{c}}$ & $0.12(0.02)$ & $0.07(0.01)$ & 0.12 & $0.13(0.06)$ \\
\hline $\mathrm{C} 45: 1^{\mathrm{c}}$ & $0.42(0.09)$ & $0.16(0.02)$ & 0.33 & $0.21(0.07)$ \\
\hline $13-\mathrm{meC} 45^{\mathrm{c}}$ & 0.00 & 0.00 & 0.00 & $0.04(0.03)$ \\
\hline $13,17-\operatorname{dimeC} 45^{\mathrm{c}}$ & $0.37(0.08)$ & $0.18(0.02)$ & 0.34 & $0.43(0.13)$ \\
\hline
\end{tabular}

${ }^{\mathrm{a}}$ Mean percent (SD) of total hydrocarbon composition. Compounds are listed in elution order

${ }^{\mathrm{b}}$ Acronyms for hydrocarbons are derived as follows: location of methyl groups (X-me), the total number of carbons (CXX) in the hydrocarbon component excluding the methyl branch(es), and the number of double bonds following a colon (CXX:Y)

${ }^{\mathrm{c}}$ These hydrocarbons were not reported for I. minor pseudergates or fecal pellets in Haverty et al. (2005)

${ }^{\mathrm{d}}$ An isomeric mixture or two or more compounds co-eluted in this peak

Pasteur pipette mini-columns. The resulting hydrocarbon fractions were evaporated to dryness under a stream of nitrogen and redissolved in $60 \cdot 1$ of $n$-hexane for gas chromatographymass spectrometry (GC-MS) analysis. A $3-\mu l$ aliquot was injected into the GC-MS.

GC-MS analyses were performed on an Agilent 6890 gas chromatograph interfaced with an Agilent 5973 Mass Selective Detector, using Agilent Chemstation data analysis software (G1701CA version C.00.00). The GC-MS was equipped with an HP-1MS, fused silica capillary column (30 $\mathrm{m} \times 0.25 \mathrm{~mm}$ i.d, $0.25 \mu \mathrm{m}$ film thickness), and was operated in split mode (split ratio of 30:1), using helium as carrier gas. The column oven was programmed from 200 $320^{\circ} \mathrm{C}$ at $3{ }^{\circ} \mathrm{Cmin}^{-1}$, with a final hold of $11 \mathrm{~min}$. Electron impact (EI) mass spectra were obtained at $70 \mathrm{eV}$.

All chemicals of interest were identified by their retention times and mass spectra. Mass spectra of methylbranched alkanes were interpreted as described by Blomquist et
Table 2 Relative abundance ${ }^{\mathrm{a}}$ of hydrocarbon classes from pseudergates, alates, soldiers, and fecal pellets of Incisitermes minor (Hagen)

\footnotetext{
${ }^{\text {a }}$ Percent of total hydrocarbon composition

${ }^{\mathrm{b}}$ All peaks with co-eluting olefins and saturated compounds are summarized as olefins
}

\begin{tabular}{lcrrr}
\hline Hydrocarbon class & Pseudergates & Alates & Soldiers & Fecal pellets \\
\hline Normal Alkanes & 38.39 & 23.12 & 29.77 & 18.71 \\
Olefins $^{\text {b }}$ & 18.38 & 21.11 & 20.31 & 20.66 \\
Terminally branched methylalkanes & 3.90 & 4.49 & 5.32 & 5.19 \\
Internally branched methylalkanes & 9.01 & 7.70 & 8.88 & 8.33 \\
Dimethylalkanes & 25.24 & 36.18 & 29.79 & 37.40 \\
Trimethylalkanes & 5.09 & 7.40 & 5.92 & 9.71 \\
\hline
\end{tabular}



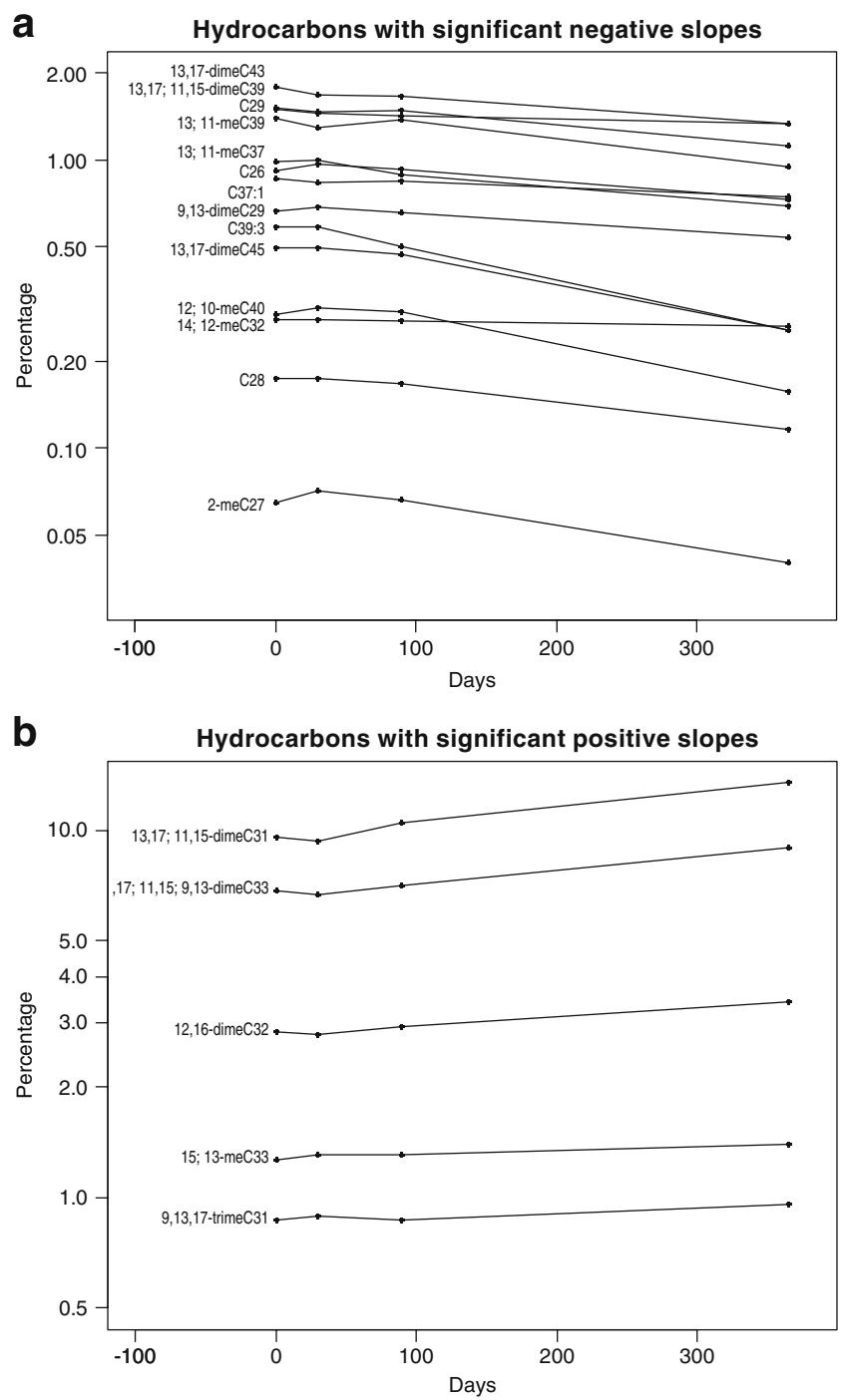

Fig. 2 Changes in percent content of individual hydrocarbons, over time, from fecal pellets of Incisitermes minor workers. a hydrocarbons with significant $(\alpha=0.05)$ negative slopes, and $\mathbf{b}$ hydrocarbons with significant positive slopes. Acronyms for hydrocarbons are derived as follows: $X$-me location of methyl groups, the total number of carbons, $C X X$ in the hydrocarbon component excluding the methyl branch(es), and $C X X: Y$ the number of double bonds following a colon

al. (1987) so as to identify methyl branch locations. Mass spectra of di- and trimethylalkanes were interpreted as described by Page et al. (1990) and Pomonis et al. (1978). Olefins were identified by their mass spectra, although double bond positions were not determined (Haverty et al., 2005).

In the text, tables, and figures, we use shorthand nomenclature to identify individual hydrocarbons or mixtures of hydrocarbons. This shorthand uses a descriptor for the location of methyl groups (X-me), the total number of carbons (CXX) in the hydrocarbon component excluding the methyl branch(es), and the number of double bonds following a colon (CXX:Y). Thus, pentacosane is represented as $n-\mathrm{C} 25$, 11methylnonacosane as 11-meC29, 13,17-dimethylhentriacontane as 13,17-dimeC31, and heptatriacontatriene as C37:3. Hydrocarbons are presented in the tables for each caste and worker fecal pellets in the order of elution from our GC-MS system.

Statistical Analysis GC-MS peak (some peaks contained more than one compound or a mixture of positional isomers) areas were converted to percentages of total hydrocarbon fraction, enabling mean $( \pm \mathrm{SD})$ relative amounts of each hydrocarbon peak for workers and alates, and overall mean $( \pm \mathrm{SD})$ of each hydrocarbon peak for the fecal pellets, to be calculated.

The percentage of each hydrocarbon peak for pellets of each aging period was transformed to the $\log$ of the percentage (dependent variable $\mathrm{Y}$ ) and regressed against the days of aging (independent variable $\mathrm{X}$ ). Hydrocarbons with slopes different from $0(\alpha=0.05)$ were separated into two groups: those with a significant positive slope and those with a significant negative slope. For each aging period $\left(0,30,90\right.$, and 365 day), an index of age $\left(I_{\text {age }}\right)$ was created by subtracting the sum of the percentages of the hydrocarbons with a negative slope over time from the sum of the percentages of the hydrocarbons with a positive slope over time $\left[\mathrm{I}_{\text {age }}=\sum\left(\mathrm{PEAK}_{\text {positive }}\right)\right.$ minus $\sum\left(\mathrm{PEAK}_{\text {negative }}\right)$, for each aging period]. The $\mathrm{I}_{\text {age }}$ for each aging period then was regressed against the aging period (R Development Core Team, 2004).

\section{Results and Discussion}

The cuticular hydrocarbons for I. minor pseudergates and fecal pellets were characterized previously (Haverty et al., 2000, 2005). The composition of the hydrocarbon mixture

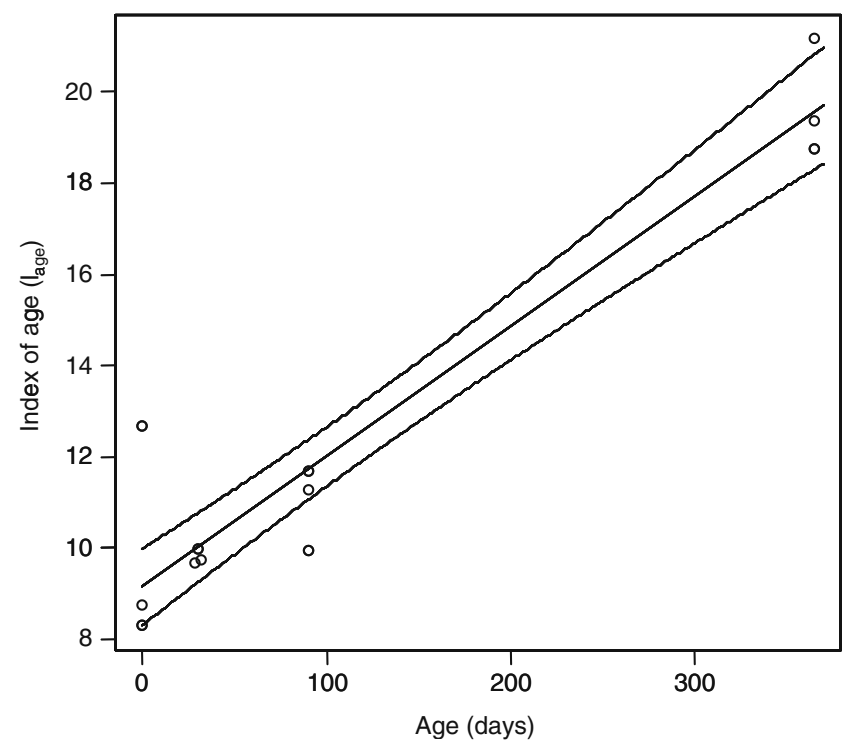

Fig. 3 Fitted line and 95\% confidence intervals for a plot of the mean of index of age $\left(\mathrm{I}_{\text {age }}\right)$ against age. Values for 30 day are jittered a small amount so that all three data points can be seen 
for this species and the hydrocarbons from their fecal pellets in the present study are displayed in Fig. 1 and summarized in Table 1.

Hydrocarbons from Termites $n$-Alkanes and dimethylalkanes were the predominant classes of hydrocarbons in all castes and in fecal pellets (Table 2), as previously reported by Haverty et al. $(2000,2005)$. n-Alkanes comprised from $23.12 \%$ to $38.39 \%$, unsaturated components from $15.21 \%$ to $19.03 \%$, terminally branched monomethylalkanes from $3.90 \%$ to $5.32 \%$, internally branched monomethylalkanes from $7.70 \%$ to $9.01 \%$, and dimethylalkanes from $25.25 \%$ to $36.18 \%$, of the total hydrocarbon content. There was also a homologous series of trimethylalkanes, representing $8.26 \%$ to $9.48 \%$ of the total hydrocarbon content.

The hydrocarbons of I. minor characterized in this study included all of the compounds reported by Haverty et al. (2005), as well as 18 additional hydrocarbons (Table 1). These additional hydrocarbons were not abundant, never representing more than $0.85 \%$ of the total hydrocarbon (as for the mixture of 12,16-dimeC34 and C35:1 in soldiers) content, and usually much less. The detection of these additional hydrocarbons in this study are likely due to the greater concentration of the extracted hydrocarbons used or, possibly, colony to colony variation.

Hydrocarbons from Termite Fecal Pellets In general, the hydrocarbons from whole-body extracts of $I$. minor were represented in extracts of fecal pellets. As with whole-body extracts of I. minor, dimethylalkanes were the predominant class of hydrocarbon, followed by olefins and normal alkanes (Table 2). Only two hydrocarbons ( $n$-C30 and 13meC30; Table 1) were found in termites and not in fecal pellets, but these were present in small quantities, less than $0.1 \%$ of the total hydrocarbon content. The lack of these two hydrocarbons in fecal pellets may be a function simply of the concentration of the extracts.

Changes in Hydrocarbons of Fecal Pellets over Time We identified 73 hydrocarbon peaks in fecal pellets of I. minor (Table 1). Of these peaks (data from non-significant slopes not reported), 19 of $73(26 \%)$ had a significant change, either positive (five) or negative (14), over time (Fig. 2). This is a much higher number of statistically significant slopes (different from 0 ), than would be expected by chance alone ( $5 \%$ of 73 peaks is $<4$ peaks).

The index, $\mathrm{I}_{\text {age }}$, for each of the three replications (A, B, and $\mathrm{C}$ at $0,30,90$, and 365 day) was plotted against the associated number of days (Fig. 3). The fitted line, with a $95 \%$ confidence interval for the means to show the variability of the replicates, had a high adjusted $R^{2}$ (=0.888) value, suggesting that it might be possible to predict fecal age by the index.
We do not know the basis by which peaks increase or decrease over the 1-year period. In general, those that increased in relative abundance tended to have higher initial relative abundances; i.e., mono-, di-, or trimethylalkanes with carbon chains of 31,32 , or 33 . Those that decreased were represented in five of the six classes of hydrocarbons, ranging from $\mathrm{C} 26$ to $\mathrm{C} 45$. Only the terminally branched hydrocarbons were not represented in peaks with negative slopes.

The composition of the hydrocarbon mixture of insects is genetically controlled (Toolson and KuperSimbrón, 1989; Kaib et al., 1991; Page et al., 1991; Coyne et al., 1994). This composition can be slightly affected by diet and environmental conditions (Hadley, 1977; Espelie et al., 1994; Chapman et al., 1995; Howard, 1998; Woodrow et al., 2000). Haverty et al. (1996) demonstrated significant seasonal variation in quantities of some hydrocarbons of Coptotermes formosanus Shiraki from Hawaii; these differences were small and associated with the production of alates. However, the qualitative mix of hydrocarbons has been shown to be stable over decades among species of cone beetles in the genus Conophthorus (Page et al., 1990).

The motivation for our study was to devise a method for the evaluation of the success or failure of drywood termite treatments, including fumigation and local application methods. With the recent classification of sulfuryl fluoride (the only fumigant active ingredient registered in California) as a greenhouse gas (Mühle et al., 2009) and the anticipated increase in local treatments, we felt that there would be considerable interest by the industry, regulatory agencies, and consumers for a simple and accurate means to determine whether or not a targeted colony/infestation is still in a structure. Our method, based on changes in hydrocarbon chemistry over time, shows promise to this end. Future research includes: (1) validating these findings for additional species of drywood termites and geographic populations of the same species, (2) validating these findings at different times of the year, and (3) exploring seasonality in pellet production and hydrocarbon quality in pellets.

Acknowledgments We thank Robin Tabuchi, Lynette Yang, Shawn Leighton, and Sara Moore for technical assistance in removing and culturing termites and the tedious work of collecting samples of termite fecal pellets. We extend thanks to the pest management professionals who provided us with the infested wood used to collect the drywood termites. This research was made possible, in part, by contract \#084-2856-5 to VRL by the California Structural Pest Control Board, Department of Consumer Affairs, Sacramento, California.

Open Access This article is distributed under the terms of the Creative Commons Attribution Noncommercial License which permits any noncommercial use, distribution, and reproduction in any medium, provided the original author(s) and source are credited. 


\section{References}

ABE, T. 1987. Evolution of life types in termites, pp. 125-128, in S. Kawano, J.H. Connell and T. Hidaka (eds). Evolution and Coadaptation in Biotic Communities, University of Tokyo Press, Tokyo.

BlomQuist, G. J., Nelson, D. R., and de Renobales, M. 1987. Chemistry, biochemistry, and physiology of insect cuticular lipids. Arch. Insect Biochem. Physiol. 6:227-265.

Boоth, W., TABUChI, R., LeWIS, V., and VARGO, E. L. 2010. Genetic diversity, colony genetic structure, colony identity and breeding structure of the western drywood termite, Incisitermes minor (Hagen). pp. 50-74 in V. R. Lewis (Principal Investigator). Assessment of Devices and Techniques for Improving Inspection and Evaluation of Treatments for Inaccessible Drywood Termite Infestations. Final Report to the California Structural Pest Control Board. pestboard.ca.gov/howdoi/research.shtml

Chapman, R. F., Espelie, K. E., and SwOrd, G. A. 1995. Use of cuticular lipids in grasshopper taxonomy: a study of variation in Schistocerca shoshone (Thomas). Biochem. Syst. Ecol. 23:383-398.

CoYne, J. A., CRITTENDEN, A. P., and MAH, K. 1994. Genetics of a pheromonal difference contributing to reproductive isolation in Drosophila. Science 265:1461-1464.

EBELING, W. 1975. Urban Entomology. University of California Press, Los Angeles.

Espelie, K. E., Chapman, R. F., and Sword, G. A. 1994. Variation in the surface lipids of the grasshopper, Schistocerca americana (Drury). Biochem. System. Ecol. 22:563-575.

GRACE, J. K. 2009. What can fecal pellets tell us about cryptic drywood termites (Isoptera: Kalotermitidae)? International Research Group on Wood Protection, Stockholm, Sweden. IRG Document IRG/ WP 09-20407, 12 pages.

Grace, J. K., and YAmAмото, R. T. 2009. Food utilization and fecal pellet production by drywood termites (Isoptera: Kalotermitidae). Sociobiology 53: 903-911.

Grace, J. K., Woodrow, R. J., and Oshiro, R. J. 2009. Expansive gallery systems of one-piece termites (Isoptera: Kalotermitidae). Sociobiology 54:1-8.

HADLEY, N. F. 1977. Epicuticular lipids of the desert tenebrionid beetle, Eleodes armata: seasonal and acclimatory effects on composition. Insect Biochem. 7:277-283.

HaVerty, M. I., Grace, J. K., Nelson, L. J., and Yamamoto, R. T. 1996. Intercaste, intercolony, and temporal variation in cuticular hydrocarbons of Coptotermes formosanus Shiraki (Isoptera: Rhinotermitidae). J. Chem. Ecol. 22: 1813-1834.

HaVerty, M. I., Woodrow, R. J., Nelson, L. J., and Grace, J. K. 2000. Cuticular hydrocarbons of termites of the Hawaiian Islands. J. Chem. Ecol. 26:1167-1191.

Haverty, M. I., Woodrow, R. J., Nelson, L. J., and Grace, J. K. 2005. Identification of termite species by the hydrocarbons in their feces. J. Chem. Ecol. 31:2119-2151.

HOWARD, R.W. 1998. Ontogenetic, reproductive, and nutritional effects on the cuticular hydrocarbons of the host-specific ectoparasitoid Cephalonomia tarsalis (Hymenoptera: Bethylidae). Ann. Entomol. Soc. Amer. 91:101-112.
Kaib, M., Brandl, R., and Bagine, R. K. N. 1991. Cuticular hydrocarbon profiles: a valuable tool in termite taxonomy. Naturwissenschaften 78:176-179.

LEWIS, V. R. 2008. Evaluation of insecticides for Western Drywood Termite control. Arthropod Management Tests 34

LEWIS, V. R, and HAVERTY, M. I. 1996. Evaluation of six techniques for control of the western drywood termite (Isoptera: Kalotermitidae) in structures. J. Econ. Entomol. 89:992-934.

LEwIS, V. R, and RUST, M. 2009. Drywood termite control: Preliminary laboratory evaluation of chemical local treatments for drywood termites. Voice of PCOC Spring pp. 14-17.

Moore, H. B. 1992. An Introduction to Wood Destroying Insects: Their Identification, Biology, Prevention, and Control. Edgell Communications, Inc., Cleveland, Ohio.

Mühle, J., Huang, J., Wiess, R. F., Prinn, R. G., Miller, B. R., Salameh, P. K., Harth, C. M., Fraser, P. J., Porter, L.W., Greally, B. R., O’Doherty, S., and Simmonds, P. G. 2009. Sulfuryl fluoride in the global atmosphere. J. Geophysical Res. 114: D05306, doi:10.1029/2008JD011162.

Page, M., Nelson, L. J., Haverty, M. I., and BlomQuist, G. J. 1990. Cuticular hydrocarbons of eight species of North American cone beetles, Conophthorus Hopkins. J. Chem. Ecol. 16:11731198.

Page, R. E., Metcalf, R. A., Metcalf, R. L., Erickson, E. H., Jr., and LAMPMAN, R. L. 1991. Extractable hydrocarbons and kin recognition in honeybee (Apis mellifera L.) J. Chem. Ecol. 17:745-756.

Page, M., Nelson, L. J., Forschler, B. T., and Haverty, M. I. 2002. Cuticular hydrocarbons suggest three lineages in Reticulitermes (Isoptera: Rhinotermitidae) from North America. Comp. Biochem. Physiol. 131B:305-324.

Pomonis, J. G., Fatland, C. F., Nelson, D. R., and Zaylskie, R. G. 1978. Insect hydrocarbons. Corroboration of structure by synthesis and mass spectrometry of mono- and dimethylalkanes. J. Chem. Ecol. 4:27-38.

R DEVElopment CORE TEAM. 2004. A language and environment for statistical computing. R Foundation for Statistical Computing, Vienna, Austria. ISBN 3-900051-07-0, URL http://www.R-project. org.

SChefFrahn, R. H., Su, N.-Y., and BuSEY, P. 1997. Laboratory and field evaluation of selected chemical treatments for control of drywood termites (Isoptera: Kalotermitidae) in wood. J. Econ. Entomol. 90: 492-502.

Su, N.-Y., and SCHEFFrAHN, R. H. 1990. Economically important termites in the United States and their control. Sociobiology 17:77-94.

Toolson, E. C. and Kuper-Simbrón, R. 1989. Laboratory evolution of epicuticular hydrocarbon composition and cuticular permeability in Drosophila pseudoobscura: effects on sexual dimorphism and thermal-acclimation ability. Evolution 43:468473.

Woodrow, R. J., Grace, J. K., Nelson, L. J., and HaVerty, M. I. 2000. Modification of cuticular hydrocarbons of Cryptotermes brevis (Isoptera: Kalotermitidae) in response to temperature and relative humidity. Environ. Entomol. 29:1100-1107. 